\title{
An Intriguing Case of Maxillary Canine with Two Canals: A Rare Entity
}

\author{
Anupriya Bhadoria ${ }^{1}$, Vineeta Nikhil ${ }^{2}$, Padmanabh Jha $^{3}$, Preeti Mishra ${ }^{4}$ \\ ${ }^{1}$ PG Student, Department of Conservative Dentistry \& Endodontics, Subharti Dental College and Hospital, \\ Meerut. \\ ${ }^{2}$ Professor and HOD, Department of Conservative Dentistry \& Endodontics, Subharti Dental College and \\ Hospital, Meerut. \\ ${ }^{3}$ Professor, Department of Conservative Dentistry \& Endodontics, Subharti Dental College and Hospital, \\ Meerut. \\ ${ }^{4}$ Senior Lecturer, Department of Conservative Dentistry \& Endodontics, Subharti Dental College and Hospital, \\ Meerut. \\ Corresponding Author: Anupriya Bhadoria
}

\begin{abstract}
One of the major causes of root canal treatment failure is inability to find and manage an extra canal (s). For achieving successful endodontic therapy, knowledge of root canal morphology and variations in the root is important. The purpose of this case report is to report a rare case of maxillary canine with two root canals. It describes the treatment of a permanent maxillary left canine having an additional canal (Vertucci's Type II canal configuration) present in a 48 year old female patient. Clinical examination revealed a maxillary canine with a previously initiated access. Radiographic examination revealed a previously initiated access in left maxillary canine, having an additional canal.
\end{abstract}

Keywords: Endodontic treatment, maxillary canine, root canal anatomy, two root canals.

\section{INTRODUCTION}

Successful endodontic treatment comprises proper diagnosis, identification of the number of root canals, meticulous cleaning, shaping and three dimensional obturation. Lack of knowledge of anatomy of the root canal system and failure to negotiate and obturate the canal in its entirety is considered one of the main reasons and significant factor for failure of root canal therapy. A major reason for failure of endodontic therapy may be undetected extra root canals. ${ }^{[1]}$ Hence, the clinician should be well versed of any anatomical variations which may alter the prognosis for treatment.

The pulp canal system is very complex with numerous divisions. Vertucci has classified the root canal configuration in eight types. Maxillary canines are majorly assumed to be single rooted with a single canal (Vertucci Type I) ${ }^{[2,3]}$ and the presence of two canals is a rare entity. Although the incidence of maxillary canine with two canals in the available literature is very low but there have been few reported cases. ${ }^{[4-7]}$ Variations in canal morphology of maxillary canine have been reported in different races. The present case report narrates an endodontic management of a single rooted maxillary canine having two canals.

\section{CASE REPORT}

A 48 year old female patient presented to the Department of Conservative Dentistry and Endodontics, Subharti Dental College and Hospital with severe pain in the upper left maxillary region since two days. The patient got root canal treatment initiated with respect to tooth number 23, two days ago from a private dentist and since then patient was having symptoms which included sharp, 
continuous, localized pain, not relieved on taking medication. Clinical examination revealed previously initiated access and tooth was tender on percussion. Preoperative radiograph showed previously initiated access and two distinct radiolucent lines running till middle third of the root and merging into one, indicative of two canals [Figure 1].

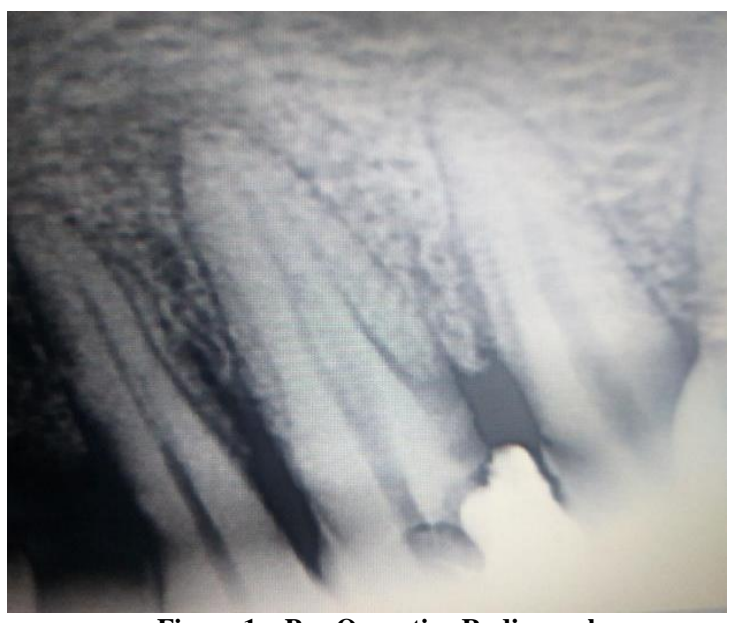

Figure 1 - Pre-Operative Radiograph

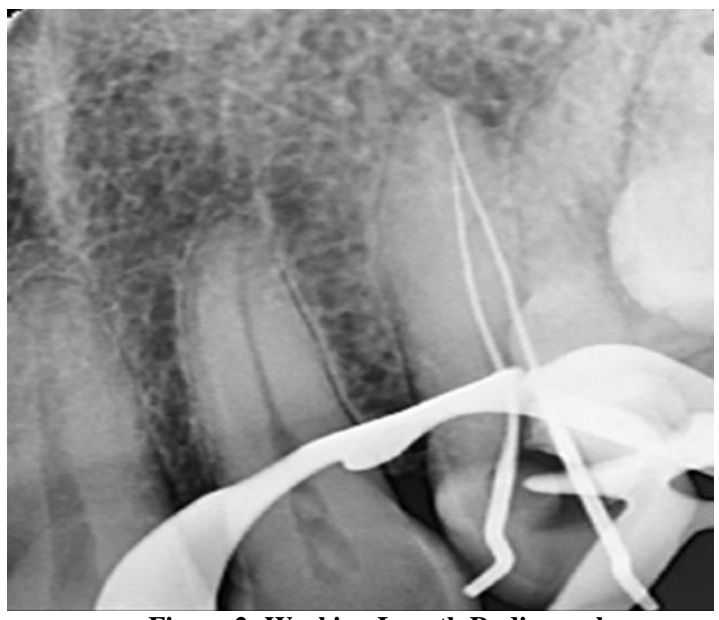

Figure 2- Working Length Radiograph

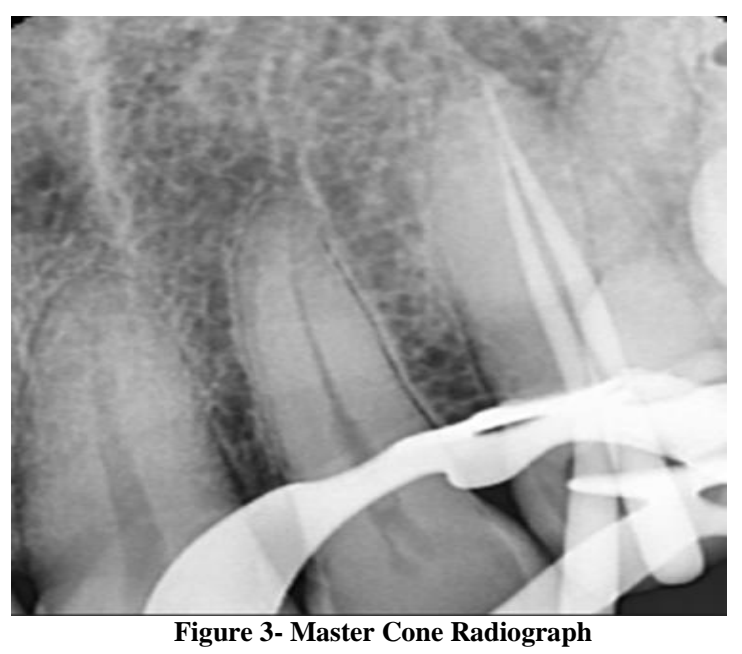

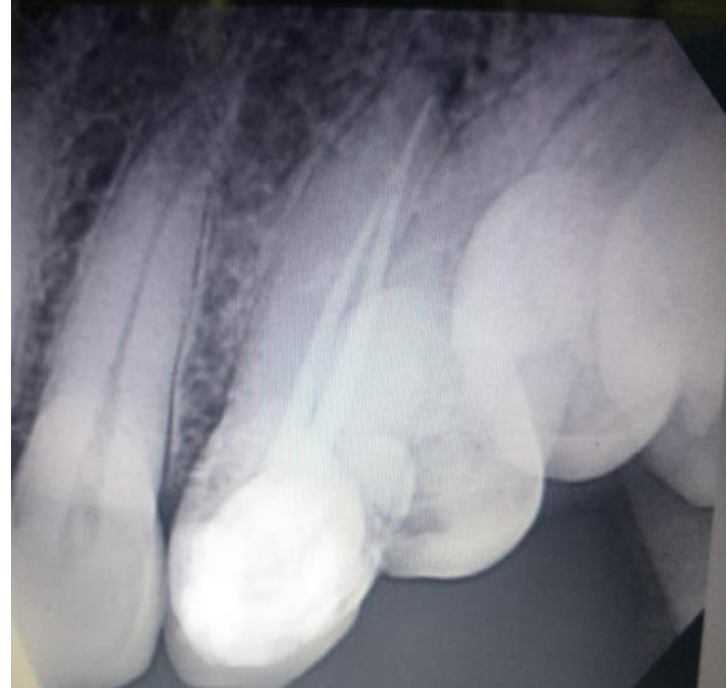

Figure 4 - Obturation and Post Endodontic Restoration

On the basis of these findings and according to American Association of Endodontics consensus (2009), the tooth was diagnosed as previously initiated endodontic therapy with symptomatic apical periodontitis. Local anaesthesia (lidocaine $2 \%$ with epinephrine 1:100,000) was administered and tooth isolated with rubber dam. Access was modified under 2.5X magnification using dental operating loupes with endo access bur No. 2. The canal orifice was present more labially than normal and on further exploration second canal orifice, lying palatal to the labial orifice was located. Working length was established by using electronic apex locator and verified by digital radiograph [Figure 2]. It was seen that the buccal canal merged with the palatal canal in the apical third of the root (Vertucci's Type II canal configuration). Shaping was done with ProTaper instruments in crown down manner sequentially and the apical preparation was done until F3 file in both the canals. A $30 \mathrm{G}$ side vented needle mounted on a syringe was placed $2 \mathrm{~mm}$ short of the working length and a $2.5 \%$ solution of sodium hypochlorite, saline and $17 \%$ ethylenediaminetetraacetic acid were used alternatively as irrigants at every change of instrument. Master cone trial was done and verified radiographically [Figure 3]. The canals were dried with paper points and the obturation was done by single cone 
technique using corresponding gutta percha cones and $\mathrm{AH}$ Plus sealer. Finally access cavity was restored using composite resin [Figure 4].

\section{DISCUSSION}

A thorough knowledge of the tooth anatomy is an important aspect to increase the success rate of endodontic therapy. Failure to locate and treat an extra canal/s is a common cause of failure of RCT. Additional canals should be suspected by the clinician if there are hints of their presence clinically and radiographically. Study by Caliskan et $a l,{ }^{[8]}$ in a Turkish population using the clearing technique reported type and number of root canals in permanent teeth. Maxillary canine with Vertucci's Type V canal configuration was found to be $2.17 \%$ and Type III was $4.35 \%$. However, they did not report Vertucci's Type II configuration. However some cases have been reported in literature which included reports by Alapati et al., ${ }^{[4]}$ Onay et al., ${ }^{[5]}$ Bolla $\mathrm{N}$ and Kavuri SR ${ }^{[6]}$ and

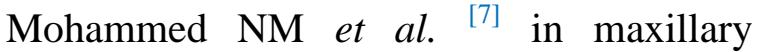
canines who found Type II canal configuration. The two distinct orifices were found to be present labially and palatally.

A careful radiographic evaluation, clinical endodontic exploration, and the use of magnification, may lead to the identification of additional canals as has been done in the present case. In addition, radiographs at different angles with a file in place may help in finding and locating additional canals. In addition, clinical examination of the pulpal floor and the association of the two canal orifices with each other are also significant. ${ }^{[7]}$ Other methods of finding missed canals include champagne bubble test, white line and red line test, transillumination, CBCT etc.

It is of utmost importance that during RCT all canals should be located and treated to attain successful treatment outcome. Prevalence of the root canal anomalies is rare however, their detection has become easier with improved techniques and equipment's like dental operating microscopes, CBCT etc.

\section{CONCLUSION}

This case emphasises the fact that clinicians should be acquainted of variations in the tooth morphology and shows that utmost care and meticulous exploration of the root canals is required to detect and treat possible additional canals.

Conflict of Interest: No potential conflict of interest relevant to this article was reported

\section{Acknowledgement: None}

\section{Source of Funding: None}

\section{REFERENCES}

1. Hulsmann M, Schafer E. Problems in gaining access to the root canal system. In: Hulsmann Michael, Schafer Edgar, editors. Problems in Endodontics: Etiology, Diagnosis and Treatment. 1 st ed. Germany: Quintessence Publishing Co Ltd; 2009. 145-72.

2. Pineda F, Kuttler Y. Mesiodistal and buccolingual roentgenographic investigation of 7,275 root canals. Oral Surg Oral Med Oral Pathol. 1972;33: 101-10.

3. Vertucci FJ. Root canal anatomy of the human permanent teeth. Oral Surg Oral Med Oral Pathol. 1984;58:589-99.

4. Alapati S, Zaatar EI, Shyama M, AlZuhair N. Maxillary canine with two root canals. Med Princ Pract. 2006;15: 74-6.

5. Onay OE, Ungor M. Maxillary Canines with two root canals. Hacettepe Dis Hekimligi Fakultesi Dergisi 2008;32:204

6. Bola N, Kavuri SR. Maxilary canine with two root canals. J Conserv Dent. 2011;14:80-2.

7. Mohammed NM, Mandorah AO, Alqashqari TA. Maxillary canine with two root canals. Saudi Endod J. 2015;5:146-8. 
8. Caliskan MK, Pehlivan Y, Sepetçioðlu F, Türkün M, Tuncer SS. Root canal morphology of human permanent teeth in a Turkish population. J Endod 1995; 21:200-4.
How to cite this article: Bhadoria A, Nikhil $\mathrm{V}$, Jha $\mathrm{P}$ et.al. An intriguing case of maxillary canine with two canals: a rare entity. International Journal of Research and Review. 2021; 8(5): 221-224. DOI: https://doi.org/10.52403/ijrr.20210529 